\title{
Attachment site selection of life stages of Ixodes ricinus ticks on a main large host in Europe, the red deer (Cervus elaphus)
}

\author{
Atle Mysterud $^{1 *}$, Idar Lauge Hatlegjerde ${ }^{2}$ and Ole Jakob Sørensen ${ }^{2}$
}

\begin{abstract}
Background: Ticks and tick-borne diseases are increasing in many areas of Europe and North America due to climate change, while land use and the increased abundances of large hosts play a more controversial role. The pattern of host selection involves a crucial component for tick abundance. While the larvae and nymphs feed on a wide range of different sized hosts, the adult female ticks require blood meal from a large host ( $>1 \mathrm{~kg})$, typically a deer, to fulfil the life cycle. Understanding the role of different hosts for abundances of ticks is therefore important, and also the extent to which different life stages attach to large hosts.
\end{abstract}

Findings: We studied attachment site selection of life stages of I. ricinus ticks on a main large host in Europe, the red deer (Cervus elaphus). We collected from 33 felled red deer pieces of skin from five body parts: leg, groin, neck, back and ear. We counted the number of larval, nymphal, adult male and adult female ticks. Nymphs (42.2\%) and adult (48.7\%) ticks dominated over larvae (9.1\%). There were more larvae on the legs (40.9\%), more nymphs on the ears (83.7\%), while adults dominated in the groins (89.2\%) and neck (94.9\%).

Conclusions: Large mammalian hosts are thus a diverse habitat suitable for different life stages of ticks. The attachment site selection reflected the life stages differing ability to move. The spatial separation of life stages may partly limit the role of deer in co-feeding transmission cycles.

Keywords: Ixodes ricinus, Ticks, Tick-borne diseases, Host preferences, Life stages

\section{Background}

Ticks are known vectors of several pathogens such as Borrelia burgdorferi sensu lato causing Lyme disease, the virus (TBEV) causing tick-borne encephalitis, and Anaplasma phagocytophilum causing tick-borne fever in livestock, to name some of the more common [1]. The distribution of ticks and its associated diseases is increasing in many areas [2,3], and understanding the mechanisms provide potential for mitigation measures. Some of these increases can be linked to warmer climate, at least at higher elevation and latitudes [4]. However, the topic of how large mammalian hosts and land use affect ticks is heavily debated [5-7]. A crucial component for tick abundance involves finding a suitable

\footnotetext{
* Correspondence: atle.mysterud@ibv.uio.no

${ }^{1}$ Centre for Ecological and Evolutionary Synthesis (CEES), Department of Biosciences, University of Oslo, P.O. Box 1066 Blindern, NO-0316 Oslo, Norway

Full list of author information is available at the end of the article
}

host. The larvae and nymphs can feed on a wide range of different sized hosts, but the adult female tick requires a blood meal from a large host $(>1 \mathrm{~kg})$ to fulfil the life cycle. Such a large host is, in many systems, typically a deer. The extent to which the dependency for a large host is limiting tick populations is nevertheless unclear, as rodents and birds are likely the more important hosts for larvae [1]. In some ecosystems in the USA, temporal variation in white-tailed deer abundance seemed less important than rodents in driving the abundance of nymphs [8], while in Scotland the abundance of red deer (Cervus elaphus) was linked to tick abundances [9]. In Europe, the distribution and density of roe deer (Capreolus capreolus) and red deer have markedly increased the last decades [10]. Red deer are considered the most important large host to ticks in many areas of Europe $[9,11]$. Nevertheless, we are lacking quantitative information on the extent of which red deer may serve different tick life stages. The attachment site selection of 
different stages on hosts also has importance for cofeeding transmission of diseases such as TBE and several other pathogens [12]. We here provide evidence that different body parts of red deer form different habitats for different life stages of ticks with potential consequences for understanding co-feeding transmission cycles.

\section{Methods}

\section{Study area}

The study area is in Kjølsdalen deer management unit $\left(57.0 \mathrm{~km}^{2}\right)$, Eid municipality, Sogn og Fjordane county in south-west of Norway $\left(61^{\circ} 54^{\prime} \mathrm{N}, 5^{\circ} 59^{\prime} \mathrm{E}\right)$. This is a coastal habitat stretching from sea level up to $500 \mathrm{~m}$ above sea level. The habitat is dominated by deciduous forest, mainly alder (Alnus incana) at low elevations mixed with aspen (Populus tremula) and hazel (Corylys avellana), while birch (Betula spp.) takes over at higher elevation. There are several plantations of Norway spruce (Picea abies) scattered in the area. Agricultural pastures are situated at valley bottoms. The area is densely population by red deer, with no other deer species in the area.

\section{Red deer data}

During the annual autumn harvest in 2013, we collected from 33 felled red deer, pieces of skin from five body parts: leg (below carpus), groin, neck, back and ear. We counted the number of larval, nymphal, adult male and adult female ticks. Most adult males were attached to adult females rather than the skin. The hair was if needed shaved off skin to enhance detection of ticks. We measured size of skin piece to enable calculation of density. We further retrieved date of harvest (Sept. $1^{\text {st }}-$ Oct. $\left.30^{\text {th }}\right)$, elevation at location of harvest (50-500 m a.s.l.), sex and age class $(0.5,1.5$ and $\geq 2.5$ years) of the deer. Data were retrieved from 4 male and 4 female calves, 3 male and 7 female yearlings and 7 male and 8 female adults.

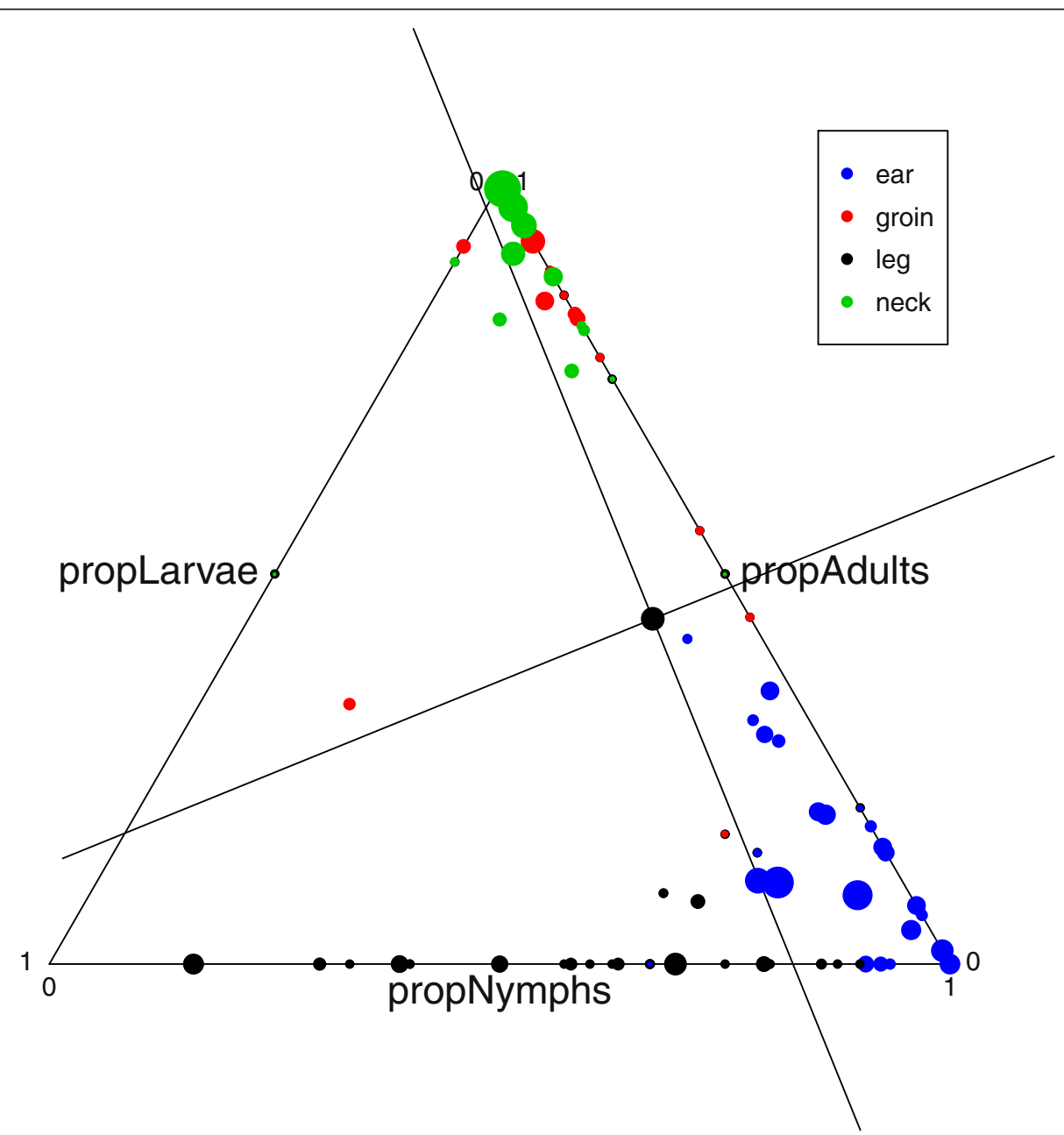

Figure 1 The proportion of different tick life stages on different body parts of red deer. Data from the back region was removed due to few ticks. Sizes of points are proportional to (sqrt) total number of ticks. 
Table 1 An overview of tick life stage placement on different body parts of red deer $(n=33)$, Norway

\begin{tabular}{lllllll}
\hline & Ear & Neck & Leg & Groin & Back & Total \\
\hline Larvae & 54 & 7 & 180 & 13 & 2 & 256 \\
Nymphs & 848 & 31 & 257 & 50 & 0 & 1186 \\
Adult males & 38 & 326 & 1 & 200 & 14 & 579 \\
Adult females & 73 & 374 & 2 & 319 & 24 & 792 \\
Larvae (\%) & 5.3 & 0.9 & 40.9 & 2.2 & 5.0 & 9.1 \\
Nymphs (\%) & 83.7 & 4.2 & 58.4 & 8.6 & 0 & 42.2 \\
Adults (\%) & 11.0 & 94.9 & 0.7 & 89.2 & 95.0 & 48.7 \\
Size of skin piece $\left(\mathrm{dm}^{2}\right)$ & 1.77 & 4.50 & 1.87 & 3.05 & 4.14 & \\
Density of all ticks $\left(/ \mathrm{dm}^{2}\right)$ & 17.3 & 4.97 & 7.13 & 5.78 & 0.29 & \\
\hline
\end{tabular}

\section{Statistical analyses}

We analysed separately the (i) abundance of ticks, (ii) density of ticks and (iii) proportion of life stages of ticks on the different body parts. (i) We analysed number of ticks using a negative binomial error known to fit such data better than Poisson $[11,13,14]$ with individual "ID"

Table 2 Parameter estimates and test statistics from mixed effects models with negative binomial error for the relationship between $(A)$ abundance and $(B)$ density of ticks on red deer, Norway

\begin{tabular}{|c|c|c|c|c|}
\hline Parameter & Estimate & Std. Error & $z$ value & $\mathbf{P}$ \\
\hline \multicolumn{5}{|l|}{ A. Abundance } \\
\hline Intercept & 7.3617 & 2.1670 & 3.400 & 0.001 \\
\hline Bodypart (groin vs leg) & 0.3586 & 0.2198 & 1.630 & 0.103 \\
\hline Bodypart (neck vs. leg) & 0.1177 & 0.2221 & 0.530 & 0.596 \\
\hline Bodypart (ear vs. leg) & 1.0613 & 0.2200 & 4.820 & $<0.001$ \\
\hline Bodypart (back vs. leg) & -2.7549 & 0.2931 & -9.400 & $<0.001$ \\
\hline Sex (f vs. m) & -0.4887 & 0.2862 & -1.710 & 0.088 \\
\hline Age (1.5 vs. 0.5) & 0.6453 & 0.3802 & 1.700 & 0.090 \\
\hline Age ( $\geq 2.5$ vs. 0.5 & 0.7498 & 0.3507 & 2.140 & 0.033 \\
\hline Julian date & -0.0189 & 0.0079 & -2.380 & 0.017 \\
\hline Elevation & -0.0015 & 0.0011 & -1.370 & 0.170 \\
\hline \multicolumn{5}{|l|}{ B. Density } \\
\hline Intercept & 5.3200 & 1.9700 & 2.710 & 0.007 \\
\hline Size of skin & $2.24 \mathrm{e}-05$ & $4.26 \mathrm{e}-06$ & 5.260 & $<0.001$ \\
\hline Bodypart (groin vs leg) & 0.0435 & 0.2030 & 0.210 & 0.830 \\
\hline Bodypart (neck vs. leg) & -0.6670 & 0.2410 & -2.760 & 0.006 \\
\hline Bodypart (ear vs. leg) & 1.0500 & 0.1950 & 5.370 & $<0.001$ \\
\hline Bodypart (back vs. leg) & -3.1800 & 0.2890 & -11.010 & $<0.001$ \\
\hline Sex (f vs. m) & -0.2120 & 0.2590 & -0.820 & 0.414 \\
\hline Age (1.5 vs. 0.5) & 0.4900 & 0.3390 & 1.440 & 0.149 \\
\hline Age ( $\geq 2.5$ vs. 0.5 & 0.5640 & 0.3140 & 1.800 & 0.072 \\
\hline Julian date & -0.0136 & 0.0071 & -1.910 & 0.056 \\
\hline Elevation & -0.0006 & 0.0010 & -0.620 & 0.533 \\
\hline
\end{tabular}

as random term using library "glmmADMB" in $\mathrm{R}$ vs. 3.1.0. (ii) For analysis of density, we entered size of skin piece as a covariate. (iii) For proportion of life stages, we used first a MANOVA (proportion of all stages as response as a function of body part) and then an ordinary GLMM for each stage. In the GLMM, the response variable was arcsin-sqrt-transformed proportions of larvae, nymphs and adults of total tick count for a given body part with body part as a categorical factor and individual "ID" as a random term using package "lme4". We weighted the regression with the (sqrt) number of ticks on the body part. For all models, we added sex, age, Julian date of harvest and elevation to the models, but considered sample sizes too small to include interactions. We used a triangle plot to visualize how different proportion of ticks attached to different body parts using library "ade4".

\section{Findings}

There were marked differences in abundance, density and proportion of tick life stages depending on the body part (Figure 1, Tables 1 and 2, MANOVA, df = 4, Pillai = 1.308, $\left.\mathrm{P}=2.2 \mathrm{e}^{-16}\right)$. Adult male and female ticks were mainly found on the neck (94.9\%), back (95.0\%) and in the groin $(89.2 \%$, Table $3 \mathrm{~A})$. Nymphs were mainly found on the ears $(83.7 \%)$ and to some extent also on legs $(58.4 \%$,

Table 3 Parameter estimates from mixed effects models with (arcsin[sqrt]) proportion of (A) larvae, (B) nymphs, and $(C)$ adult ticks as response ticks on red deer, Norway

\begin{tabular}{lllll}
\hline Parameter & Estimate & SE & Lower & Upper \\
& & $95 \% \mathrm{CL}$ & $95 \% \mathrm{CL}$ \\
& &
\end{tabular}

A. Larvae

Bodypart (groin vs. leg) $\quad-0.5594 \quad 0.0527 \quad-0.6647 \quad-0.4541$

Bodypart (neck vs. leg) $\quad-0.5670 \quad 0.0541 \quad-0.6752 \quad-0.4588$

Bodypart (ear vs. leg) $\quad-0.4536 \quad 0.0496 \quad-0.5527 \quad-0.3544$

Bodypart (back vs. leg) $\quad-0.4508 \quad 0.1075 \quad-0.6658 \quad-0.2358$

B. Nymphs

Intercept

$\begin{array}{llll}0.9479 & 0.0478 & 0.8524 & 1.0434\end{array}$

Bodypart (groin vs. leg) $\quad-0.7018 \quad 0.0646 \quad-0.8310 \quad-0.5727$

$\begin{array}{lllll}\text { Bodypart (neck vs. leg) } & -0.7835 & 0.0661 & -0.9157 & -0.6512\end{array}$

$\begin{array}{lllll}\text { Bodypart (ear vs. leg) } & 0.2680 & 0.0607 & 0.1466 & 0.3894\end{array}$

Bodypart (back vs. leg) $\quad-0.9450 \quad 0.1310 \quad-1.2071 \quad-0.6830$

C. Adults

$\begin{array}{lllll}\text { Intercept } & 0.0230 & 0.0447 & -0.0664 & 0.1124\end{array}$

$\begin{array}{lllll}\text { Bodypart (groin vs. leg) } & 1.2677 & 0.0608 & 1.1461 & 1.3894\end{array}$

$\begin{array}{lllll}\text { Bodypart (neck vs. leg) } & 1.3564 & 0.0622 & 1.2319 & 1.4809\end{array}$

$\begin{array}{lllll}\text { Bodypart (ear vs. leg) } & 0.2526 & 0.0572 & 0.1382 & 0.3669\end{array}$

$\begin{array}{lllll}\text { Bodypart (back vs. leg) } & 1.3816 & 0.1232 & 1.1352 & 1.6280\end{array}$

Individual ID of red deer was a random term in the models. 
Table 3B). Larvae were mainly found on legs (40.9\%, Table 3C). Number of ticks was highest on ears, similar on groin, neck and leg, and lower on the back (Tables 1 and 2A). The higher abundance of ticks on adults compared to calves (Table 2A) was not significant when correcting for size of skin sample, i.e. densities were similar (Table 2B). Density of ticks was higher on the ear (17.3 ticks $\left./ \mathrm{dm}^{2}\right)$ than on the leg $\left(7.13\right.$ ticks $\left./ \mathrm{dm}^{2}\right)$, the groin $\left(5.78 \mathrm{ticks} / \mathrm{dm}^{2}\right)$ and the neck $\left(4.97 \mathrm{ticks} / \mathrm{dm}^{2}\right)$, with significantly lower density on the back $\left(0.29\right.$ ticks $/ \mathrm{dm}^{2}$, Table 2B). There were fewer ticks and lower density of ticks on red deer harvested late in the fall (Julian date; Sept. $1^{\text {st }}$ - Oct. $30^{\text {th }}$ ), while elevation did not affect number or density of ticks notably. Effects of sex or age class did not have a significant impact on density (Table 2B).

\section{Discussion}

The role of large sized hosts for determining tick abundances and their role in the transmission cycles of disease remain controversial $[7,15,16]$. We provide insight on how different stages of ticks select different body parts for attachment on a main large host in Europe, the red deer. The attachment site selection reflected the life stages differing ability to move. The larvae were mainly found on legs and ears with a short distance to move after encountering the host, with nymphs mainly on ears and some on legs, while adult ticks moved longer distances to the neck and groin region. Deer species are most often discussed in general terms when it comes to their impact on tick ecology. However, deer species may differ in importance as hosts for ticks for a number of reasons, and patterns of attachment site selection of ticks may also differ among deer species. Larger species or age classes of deer would mean longer distances to move to reach a given location for a tick entering the leg or head. A study on attachment site selection on roe deer reported similarly that larvae mainly attached to legs (and head), nymphs on the head and adults on neck [12]. However, fewer adult ticks were found on ears of roe deer and red deer calves compared to adults [17]. Further, feeding niches of deer species differ. We would expect large browsers such as moose (Alces alces) to have fewer ticks on the head due to more feeding on trees and less on ground vegetation and thus a lower opportunity for ticks to enter the head. Indeed, fewer ticks and a higher proportion of adult ticks and lower proportion of larval and nymphal ticks were found on moose ears compared to ears from red deer and roe deer [17]. Deer ears are often used in tick burden studies due to ease of sampling by hunters [17], but our study also highlights that sampling of ears may give biased estimates of the overall proportion of tick life stages. Our data derive from sampling in Autumn. Similar studies in the main questing period in early summer may affect proportions of life stages if questing times differ [18], but are unlikely to affect attachment site selection. Cofeeding of larval and nymphal ticks is important for transmission of TBE and may occur for several other pathogens [19]. The partial spatial separation of tick stages on deer may partly limit the opportunity for such transmission [12], though legs and ears do have both larvae and nymphs. Our study thus has potential implications for understanding tick disease transmission, and highlights and suggests that more studies are needed for understanding how different species of deer function as hosts for ticks.

\section{Competing interests}

The authors declare that they have no competing interests.

\section{Authors' contributions}

AM, ILH and OJS designed the study. AM carried out data analysis and drafted the manuscript. All authors read and approved the final version of the manuscript.

\section{Acknowledgements}

We are grateful to the hunters for help in sampling, to Lars Qviller for initial discussions, to an anonymous referee for several useful suggestions, and to Christophe Bonenfant for sharing script used for Figure 1. This study was financially supported by the project TickDeer (203786/E40), Nord-Trøndelag University College and Sogn and Fjordane County Council.

\section{Author details}

${ }^{1}$ Centre for Ecological and Evolutionary Synthesis (CEES), Department of Biosciences, University of Oslo, P.O. Box 1066 Blindern, NO-0316 Oslo, Norway. ${ }^{2}$ Nord-Trøndelag University College, Faculty of Nature Resource Sciences, P.O. Box 2501NO-7729 Steinkjer, Norway.

Received: 18 July 2014 Accepted: 29 October 2014

Published online: 13 November 2014

\section{References}

1. Sonenshine DE, Roe RM: Biology of Ticks. Oxford: Oxford University Press; 2014.

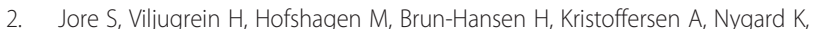
Ottesen P, Saevik B, Ytrehus B, Brun E: Multi-source analysis reveals latitudinal and altitudinal shifts in range of Ixodes ricinus at its northern distribution limit. Parasite Vector 2011, 4:84.

3. Jore $S$, Vanwambeke $S O$, Viljugrein $H$, Isaksen $K$, Kristoffersen $A B$, Woldehiwet Z, Johansen B, Brun E, Brun-Hansen H, Westerman S, Larsen I-L, Ytrehus $B$, Hofshagen M: Climate and environmental change drives Ixodes ricinus geographical expansion at the northern range margin. Parasite Vector 2014, 7:11.

4. Jaenson TGT, Eisen L, Comstedt P, Mejlon HA, Lindgren E, Bergström S, Olsen B: Risk indicators for the tick Ixodes ricinus and Borrelia burgdorferi sensu lato in Sweden. Med Vet Entomol 2009, 23:226-237.

5. Wood CL, Lafferty KD: Biodiversity and disease: a synthesis of ecological perspectives on Lyme disease transmission. Trends Ecol Evol 2013, 28:239-247.

6. Wood CL, Lafferty KD, DeLeo G, Young HS, Hudson PJ, Kuris AM: Does biodiversity protect humans against infectious disease? Ecology 2014, 95:817-832.

7. Ostfeld RS, Keesing F: Straw men don't get Lyme disease: response to Wood and Lafferty. Trends Ecol Evol 2013, 28:502-503.

8. Ostfeld RS, Canham CD, Oggenfuss K, Winchcombe RJ, Keesing F: Climate, deer, rodents, and acorns as determinants of variation in Lyme-disease risk. Plos Biol 2006, 4:1058-1068.

9. Gilbert L, Maffey GL, Ramsay SL, Hester AJ: The effect of deer management on the abundance of Ixodes ricinus in Scotland. Ecol Appl 2012, 22:658-667. 
10. Milner JM, Bonenfant C, Mysterud A, Gaillard J-M, Csányi S, Stenseth NC: Temporal and spatial development of red deer harvesting in Europe biological and cultural factors. J Appl Ecol 2006, 43:721-734.

11. Qviller L, Risnes-Olsen N, Bærum KM, Meisingset EL, Loe LE, Ytrehus B, Viljugrein $\mathrm{H}$, Mysterud A: Landscape level variation in tick abundance relative to seasonal migration pattern of red deer. PloS One 2013, 8:e71299.

12. Kiffner $C$, Lödige $C$, Alings $M$, Rühe F: Attachment site selection of ticks on roe deer, Capreolus capreolus. Exp Appl Acarol 2011, 53:79-94.

13. James MC, Bowman AS, Forbes KJ, Lewis F, McLeod JE, Gilbert L:

Environmental determinants of Ixodes ricinus ticks and the incidence of Borrelia burgdorferi sensu lato, the agent of Lyme borreliosis, in Scotland. Parasitology 2013, 140:237-246.

14. Qviller L, Grøva L, Viljugrein H, Klingen I, Mysterud A: Temporal pattern of questing tick Ixodes ricinus density at differing elevations in the coastal region of western Norway. Parasite Vector 2014, 7:179.

15. Randolph SE, Dobson ADM: Pangloss revisisted: a critique of the dilution effect and the biodiversity-buffers-disease paradigm. Parasitology 2012, 139:847-863.

16. Lafferty KD, Wood CL: It's a myth that protection against disease is a strong and general service of biodiversity conservation: Response to Ostfeld and Keesing. Trends Ecol Evol 2013, 28:503-504.

17. Handeland K, Qviller L, Vikøren T, Viljugrein $H$, Lillehaug A, Davidson RK: Ixodes ricinus infestation in free-ranging cervids in Norway - a study based upon ear examinations of hunted animals. Vet Parasitol 2013, 195:142-149.

18. Dobson ADM, Finnie TJR, Randolph SE: A modified matrix model to describe the seasonal population ecology of the European tick Ixodes ricinus. J Appl Ecol 2011, 48:1017-1028.

19. Randolph SE, Gern L, Nuttall PA: Co-feeding ticks: epidemiological significance for tick-borne pathogen transmission. Parasitol Today 1996, 12:472-479.

doi:10.1186/s13071-014-0510-x

Cite this article as: Mysterud et al:: Attachment site selection of life stages of Ixodes ricinus ticks on a main large host in Europe, the red deer (Cervus elaphus). Parasites \& Vectors 2014 7:510.

\section{Submit your next manuscript to BioMed Central and take full advantage of:}

- Convenient online submission

- Thorough peer review

- No space constraints or color figure charges

- Immediate publication on acceptance

- Inclusion in PubMed, CAS, Scopus and Google Scholar

- Research which is freely available for redistribution 